\title{
SKOPOLETIN SENYAWA FENILPROPANOID DARI KULIT UMBI UBI JALAR (IPOMOEA BATATAS L.) VARIETAS IR-MELATI
}

\author{
Citra Putri Pramitha ${ }^{1}$, Alfinda Novi Kristanti ${ }^{2}$, dan Nanik Siti Aminah ${ }^{2}$ \\ ${ }^{1}$ Mahasiswa Prodi S-1 Kimia, Departemen Kimia, Fakultas Sains dan Teknologi, \\ Universitas Airlangga, Surabaya \\ ${ }^{2}$ Departemen Kimia, Fakultas Sains dan Teknologi, \\ Universitas Airlangga, Surabaya \\ *email:nanik-s-a@fst.unair.ac.id
}

Received 3 August 2016

Accepted 30 November 2016

\begin{abstract}
Abstrak
Suatu senyawa golongan fenil propanoid dengan nama "skopoletin" telah berhasil diisolasi dari kulit umbi ubi jalar (Ipomoea batatas L.) varietas IR-melati. Ekstraksi senyawa dilakukan dengan metode maserasi menggunakan pelarut metanol, dilanjutkan dengan partisi menggunakan $n$-heksana dan etil asetat. Pemisahan dan pemurnian senyawa dilakukan menggunakan teknik kromatografi kolom gravitasi. Struktur senyawa dianalisis berdasarkan data spektroskopi UV/Vis, 1D, dan 2D-NMR.
\end{abstract}

Kata kunci : fenilpropanoid, skopoletin, Ipomoea batatas L.

\begin{abstract}
A compound of phenylpropanoid group called scopoletin has been isolated from the tuber peel of sweet potato (Ipomoea batatas L) "IR-melati var". Extraction of this compound was done by maceration method using methanol solvent, followed by partition with n-hexane and ethyl acetate. Separation and purification of compound was undertaken by gravity column chromatography techniques. Chemical structure of the scopoletin was confirmed by UV/Vis, 1D and 2D NMR data.
\end{abstract}

Keywords : phenylpropanoid, scopoletin, Ipomoea batatas L.

\section{Pendahuluan}

Ipomoea batatas L. merupakan jenis tanaman umbi-umbian yang biasa disebut ubi jalar dengan morfologi tanaman meliputi akar, batang, daun, bunga, buah, dan biji. Tanaman ini termasuk dalam famili Convolvulaceae (Shekhar,et al., 2015). Indonesia memiliki berbagai macam jenis ubi jalar, salah satunya adalah ubi jalar putih atau biasa disebut ubi IR-melati di daerah Malang. Tanaman ini merupakan sayuran yang sangat bergizi, mengandung berbagai vitamin, asam amino, mineral, serat makanan, senyawa fenolik, tokoferol, $\beta$-karoten (Wu, et al., 2008).
Bagian daging umbi ubi jalar memiliki konsentrasi senyawa fenolik lebih rendah dibandingkan dengan bagian kulitnya (Oki, et al., 2002b). Ada berbagai macam senyawa fenolik seperti asam fenolat dan flavonoid yang ditemukan dalam ubi jalar (Islam, et al., 2002), tetapi dari sebagian besar penelitian yang dipublikasikan hanya dibahas tentang kandungan antosianin dalam ubi jalar (Ipomoea batatas L.) varietas IR-melati.

Berdasarkan uraian di atas, maka dilakukan penelitian terhadap ubi jalar putih (ubi IR-melati) pada bagian kulit umbinya. Penelitian ini bertujuan untuk mengisolasi dan mengidentifikasi senyawa fenolik yang terdapat dalam kulit 
umbi ubi jalar (Ipomoea batatas L.) varietas IR-melati.

\section{Metode Penelitian}

Alat dan Bahan

Kromatografi kolom gravitasi menggunakan silika gel G-60 dan analisis Kromatografi Lapis Tipis (KLT) menggunakan pelat silika gel $\mathrm{GF}_{254}$. Spektrum UV ditetapkan dengan spektrometer Shimadzu UV-1800 dan spektrum ${ }^{1} \mathrm{H}-\mathrm{NMR},{ }^{13} \mathrm{C}-\mathrm{NMR}$, HSQC, HMBC, dan NOESY ditentukan dengan spektrometer BRUKER $600 \mathrm{MHz}$ menggunakan pelarut metanol- $d 4$.

Bahan tanaman yang digunakan dalam penelitian ini adalah kulit umbi Ipomoea batatas L varietas IR-melati. yang diperoleh dari Dusun Kepatihan, Desa Pamotan, Kecamatan Dampit, Kota Malang, Provinsi Jawa Timur. Kulit umbi yang dimaksud di sini adalah hasil kupasan kulit dari umbi Ipomoea batatas $\mathrm{L}$ varietas IR-melati.

\section{Prosedur Penelitian \\ Ekstraksi dan isolasi}

Sampel kering Ipomoea batatas L varietas IR-melati $(510 \mathrm{~g})$ diekstraksi dengan metode maserasi menggunakan pelarut metanol sebanyak dua kali. Setelah disaring, maserat dipisahkan dan diuapkan pelarutnya untuk mendapatkan ekstrak metanol. Ekstrak metanol selanjutnya dipartisi dengan $n$-heksana dan etil asetat. Ekstrak etil asetat difraksinasi dengan kromatografi kolom gravitasi menggunakan eluen campuran $n$ heksana : etil asetat yang kepolarannya ditingkatkan secara gradien hingga menghasilkan tujuh fraksi utama yakni A, B, C, D, E, F, dan G. Pemisahan terhadap fraksi G, selanjutnya dilakukan menggunakan kromatografi kolom gravitasi kembali (eluen $n$-heksana : etil asetat yang kepolarannya ditingkatkan secara gradien) untuk memperoleh subfraksi G1 yang merupakan isolat murni berdasarkan hasil uji dengan kromatografi lapis tipis (KLT) menggunakan tiga sistem eluen yang berbeda. Penentuan struktur molekul dilakukan dengan menggunakan data spektroskopi UV/Vis dan NMR (1D dan 2D).

\section{Hasil dan Pembahasan}

Skopoletin berupa serbuk berwarna putih sebanyak 3,1 mg. Data spektrum UV/Vis memberikan serapan maksimum pada $\lambda_{\text {maks }}(\log \varepsilon) 230 \mathrm{~nm}(4,07), 254 \mathrm{~nm}$ (3,70), $298 \mathrm{~nm}(3,73)$, dan 345,5 nm (4,03). Pemberian pereaksi geser $\mathrm{NaOH}$ memberikan $\lambda_{\text {maks }}$ pada $241,5 \mathrm{~nm}$ dan $392 \mathrm{~nm}$.

Data spektrum ${ }^{1} \mathrm{H}-\mathrm{NMR}$ (metanol-d4) memberikan pergeseran pada $\delta 3,93(3 \mathrm{H}$, $\left.\mathrm{s}, \mathrm{OCH}_{3}\right), 6,22(1 \mathrm{H}, \mathrm{d}, J=9,5 \mathrm{~Hz}, \mathrm{H}-3)$, 6,79 (1H, s, H-4), 7,14 (1H, s, H-5), dan 7,88 $(1 \mathrm{H}, \mathrm{d}, J=9,5 \mathrm{~Hz}, \mathrm{H}-8)$. Data spektrum ${ }^{13} \mathrm{C}-\mathrm{NMR}$ (metanol-d4) memberikan pergeseran pada $\delta 56,8(\mathrm{~s}$, $\left.\mathrm{OCH}_{3}\right), 103,9$ (s, C-8), 109,9 (s, C-5), 112,5 (s, C-2), 112,6 (s, C-9), 146,1 (s, C4), 147,2 (s, C-6), 151,5 (s, C-10), 153,1 (s, C-7), dan 164,1 (s, C-2).

Analisis spektrum UV, mengindikasikan adanya kerangka kumarin. Setelah penambahan $\mathrm{NaOH}$, terjadi pergeseran batokromik dari $\boldsymbol{\lambda}_{\text {maks }}$ $230 \mathrm{~nm}$ menjadi $241,5 \mathrm{~nm}$ dan $\lambda_{\text {maks }} 345,5$ $\mathrm{nm}$ menjadi $392 \mathrm{~nm}$. Adanya pergeseran serapan maksimum menuju ke panjang gelombang yang lebih besar, menunjukkan bahwa terdapat gugus hidroksi yang terikat pada cincin aromatik.

Spektrum ${ }^{13} \mathrm{C}$-NMR yang dilengkapi dengan DEPT 90 dan DEPT 135 memperlihatkan adanya 10 sinyal karbon yang terdiri dari satu sinyal karbon metil berupa gugus metoksi $\left(\boldsymbol{\delta}_{\mathrm{C}} 56,8 \mathrm{ppm}\right)$, empat sinyal karbon metin $\left(\boldsymbol{\delta}_{\mathrm{C}} 103,9\right.$; 109,9 ; 112,5; dan 146,1 ppm), dan lima sinyal karbon kuarterner $\left(\boldsymbol{\delta}_{\mathrm{C}} 112,6 ; 147,2\right.$; 151,$5 ; 153,1$; dan 164,1 ppm). Dari kelima sinyal karbon kuarterner tersebut terdapat dua sinyal karbon oksiaril $\left(\boldsymbol{\delta}_{\mathrm{C}}\right.$ 
$147,2 \mathrm{ppm}$ dan $\left.\boldsymbol{\delta}_{\mathrm{C}} 153,1 \mathrm{ppm}\right)$ dan satu sinyal karbon gugus karbonil $\left(\boldsymbol{\delta}_{\mathrm{C}} 164,1\right.$ ppm).

Spektrum ${ }^{1} \mathrm{H}-\mathrm{NMR}$ senyawa fenolik dalam metanol-d4 memperlihatkan adanya dua sinyal proton aromatik, yaitu sinyal singlet pada $\boldsymbol{\delta}_{\mathrm{H}} 6,79 \mathrm{ppm}$ dan $\boldsymbol{\delta}_{\mathrm{H}}$

$7,14 \mathrm{ppm}$. Sinyal tersebut menandakan adanya dua proton aromatik yang terikat pada posisi para. Sinyal proton lainnya pada spektrum ${ }^{1} \mathrm{H}-\mathrm{NMR}$ memperlihatkan adanya dua sinyal doublet $(J=9,5 \mathrm{~Hz})$ pada $\boldsymbol{\delta}_{\mathrm{H}} 6,22 \mathrm{ppm}$ dan $\boldsymbol{\delta}_{\mathrm{H}} 7,88 \mathrm{ppm}$ yang menandakan adanya proton olefinik pada posisi cis. Serta satu sinyal singlet yang menandakan adanya gugus metoksi pada $\boldsymbol{\delta}_{\mathrm{H}} 3,93 \mathrm{ppm}$. Analisis spektrum ${ }^{13} \mathrm{C}-\mathrm{NMR}$ dan ${ }^{1} \mathrm{H}-\mathrm{NMR}$ menunjukkan adanya kumarin disubstitusi. Analisis spektrum ${ }^{1} \mathrm{H}-\mathrm{NMR}$ menunjukkan adanya satu susbtituen gugus metoksi. Dengan demikian dapat diduga bahwa substituen satu lagi adalah gugus hidroksi, karena hasil analisis menggunakan spektroskopi UV/Vis memperlihatkan adanya pergeseran batokromik. Pergeseran tersebut menunjukkan bahwa terdapat gugus fenolik dalam struktur senyawa. Sinyal yang menunjukkan adanya gugus hidroksi tidak tampak pada spekrum ${ }^{1} \mathrm{H}-\mathrm{NMR}$ dikarenakan pelarut yang digunakan adalah metanol- $d 4$. Analisis dari spektrum COSY menunjukkan adanya korelasi antara kedua sinyal proton olefinik $\left(\boldsymbol{\delta}_{\mathrm{H}}\right.$ 6,22 ppm dan $\left.\boldsymbol{\delta}_{\mathrm{H}} 7,88 \mathrm{ppm}\right)$ yang terikat pada C-3 dan C-4.

Tabel-1 Data NMR senyawa skopoletin (7-hidroksi-6-metoksi-kroman-2-on) hasil isolasi

\begin{tabular}{cccccc}
\hline & & \multicolumn{5}{c}{ 7-hidroksi-6-metoksi-kroman-2-on } & \\
$\mathrm{C}$ & $\boldsymbol{\delta}_{\mathrm{H}}($ mult,$J)(\mathrm{ppm})$ & $\begin{array}{c}\boldsymbol{\delta}_{\mathrm{C}} \\
(\mathrm{ppm})\end{array}$ & $\begin{array}{c}\text { COSY } \\
(\mathrm{ppm})\end{array}$ & $\begin{array}{c}\text { NOESY } \\
(\mathrm{ppm})\end{array}$ & HMBC \\
\hline 1 & - & - & - & - & - \\
2 & - & 164,1 & - & - & - \\
3 & $6,22(d, J=9,5 \mathrm{~Hz})$ & 112,5 & 7,88 & 7,88 & $\mathrm{C}-2, \mathrm{C}-9$ \\
4 & $7,88(d, J=9,5 \mathrm{~Hz})$ & 146,1 & 6,22 & 6,$22 ; 7,14$ & $\mathrm{C}-2, \mathrm{C}-5, \mathrm{C}-10$ \\
5 & $7,14(s)$ & 109,9 & - & 3,$93 ; 7,88$ & $\mathrm{C}-4, \mathrm{C}-6, \mathrm{C}-7, \mathrm{C}-10$ \\
6 & - & 147,2 & - & - & - \\
7 & - & 153,1 & - & - & - \\
8 & $6,79(s)$ & 103,9 & - & - & $\mathrm{C}-6, \mathrm{C}-7, \mathrm{C}-9, \mathrm{C}-10$ \\
9 & - & 112,6 & - & - & - \\
10 & - & 151,5 & - & - & - \\
$6-\mathrm{OCH} 3$ & $3,93(s)$ & 56,8 & - & 7,14 & $\mathrm{C}-6$ \\
\hline
\end{tabular}

Spektrum HSQC memperlihatkan lima korelasi sinyal proton, yaitu korelasi $\boldsymbol{\delta}_{\mathrm{H}}$ $6,22(d, J=9,5 \mathrm{~Hz})$ dengan $\boldsymbol{\delta}_{\mathrm{C}} 112,5$; korelasi $7,88(d, J=9,5 \mathrm{~Hz})$ dengan $\boldsymbol{\delta}_{\mathrm{C}}$ 146,1 ; korelasi $\delta_{\mathrm{H}} 7,14(s)$ dengan $\delta_{\mathrm{C}}$ 109,9 ; korelasi $\boldsymbol{\delta}_{\mathrm{H}} 6,79(s)$ dengan 103,9; dan korelasi $\boldsymbol{\delta}_{\mathrm{H}} 3,93(s)$ dengan $\boldsymbol{\delta}_{\mathrm{C}} 56,8$. Berdasarkan analisis spektrum HMBC, proton olefinik pada $\boldsymbol{\delta}_{\mathrm{H}} \quad 7,88 \mathrm{ppm}$ berkorelasi dengan C-2 ( $\left.\boldsymbol{\delta}_{\mathrm{C}} 164,1 \mathrm{ppm}\right)$, C-5 $\left(\boldsymbol{\delta}_{\mathrm{C}} 109,9 \mathrm{ppm}\right)$, dan C-10 $\left(\boldsymbol{\delta}_{\mathrm{C}} 151,5\right.$ ppm). Hal ini menunjukkan bahwa proton $\boldsymbol{\delta}_{\mathrm{H}} 7,88 \mathrm{ppm}$ terikat pada C-4. Dengan demikian, proton olefinik pada $\boldsymbol{\delta}_{\mathrm{H}} 6,22$ ppm terikat pada C-3. Proton olefinik pada $\delta_{\mathrm{H}} 6,22$ ppm berkorelasi dengan $\mathrm{C}-2$ $\left(\boldsymbol{\delta}_{\mathrm{C}} 164,1 \mathrm{ppm}\right)$ dan C-9 ( $\left.\boldsymbol{\delta}_{\mathrm{C}} 112,6 \mathrm{ppm}\right)$. Proton aromatik pada $\delta_{\mathrm{H}} 7,14$ ppm berkorelasi dengan C-4 ( $\left.\boldsymbol{\delta}_{\mathrm{C}} 146,1 \mathrm{ppm}\right)$, C-6, C-7 dan C-10 ( $\boldsymbol{\delta}_{\mathrm{C}} 151,5$ ppm). Adanya korelasi dari sinyal proton $\boldsymbol{\delta}_{\mathrm{H}}$ 7,14 ppm dengan C-4 menunjukkan bahwa proton tersebut terikat pada C-5. 
Korelasi sinyal proton $\boldsymbol{\delta}_{\mathrm{H}} \quad 7,14$ ppm.Karena proton $\boldsymbol{\delta}_{\mathrm{H}} 7,14$ ppm terikat pada C-5, maka proton $\delta_{\mathrm{H}} 6,79 \mathrm{ppm}$ terikat pada C-8. Proton aromatik pada $\boldsymbol{\delta}_{\mathrm{H}}$ 6,79 ppm berkorelasi dengan C-6, C-7, C$9\left(\boldsymbol{\delta}_{\mathrm{C}} 112,6 \mathrm{ppm}\right)$, dan $\mathrm{C}-10\left(\boldsymbol{\delta}_{\mathrm{C}} 151,5\right.$ ppm). Sinyal proton gugus metoksi $\boldsymbol{\delta}_{\mathrm{H}}$ 3,93 ppm berkorelasi dengan sinyal karbon pada $\boldsymbol{\delta}_{\mathrm{C}} 147,2$ ppm. Hal ini menunjukkan bahwa gugus hidroksi terikat pada karbon dengan sinyal $\boldsymbol{\delta}_{\mathrm{C}}$ 153,1 ppm. Dari hasil analisis spektrum HMBC, atom karbon yang terletak pada C-6 dan C-7 belum dapat ditentukan.

Penempatan $\boldsymbol{\delta}_{\mathrm{C}} 147,2 \mathrm{ppm}$ dan $\boldsymbol{\delta}_{\mathrm{C}}$ 153,1 ppm pada C-6 atau C-7 dapat dilihat dari hasil analisis spektrum NOESY. Hasil analisis spektrum NOESY menujukkan bahwa terdapat korelasi sinyal proton antara $\boldsymbol{\delta}_{\mathrm{H}} 3,93 \mathrm{ppm}$ dengan $\boldsymbol{\delta}_{\mathrm{H}} 7,14$ ppm; $\boldsymbol{\delta}_{\mathrm{H}} 7,88$ ppm dengan $\boldsymbol{\delta}_{\mathrm{H}} 7,14$ ppm; dan $\boldsymbol{\delta}_{\mathrm{H}}$ 7,88 ppm dengan $\boldsymbol{\delta}_{\mathrm{H}} 6,22$ ppm. Adanya korelasi sinyal proton antara $\boldsymbol{\delta}_{\mathrm{H}}$ 3,93 ppm dengan $\boldsymbol{\delta}_{\mathrm{H}}$ 7,14 ppm pada spektrum NOESY menunjukkan bahwa atom karbon $\left(\boldsymbol{\delta}_{\mathrm{C}} 147,2 \mathrm{ppm}\right)$ terletak pada posisi C-6. Dengan demikian, atom karbon yang terletak pada posisi C-7 adalah atom karbon ( $\left.\boldsymbol{\delta}_{\mathrm{C}} 153,1 \mathrm{ppm}\right)$. Berdasarkan data spektrum ${ }^{1} \mathrm{H}-\mathrm{NMR},{ }^{13} \mathrm{C}$ NMR, COSY, NOESY, HSQC, dan HMBC (Tabel 1), maka senyawa hasil isolasi diprediksi sebagai skopoletin (7hidroksi-6-metoksi-kroman-2-on) (Gambar 1).<smiles></smiles>

(a)<smiles>COc1cc2ccc(=O)oc2c(C=O)c1O</smiles>

(b)

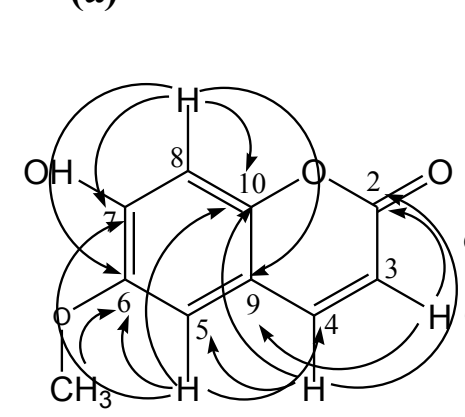

(c)

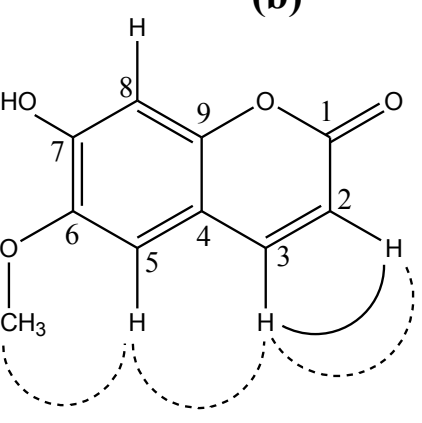

(d)

Gambar-1 Senyawa skopoletin: (a) ${ }^{1} \mathrm{H}-\mathrm{NMR}$ (b) ${ }^{13} \mathrm{C}-\mathrm{NMR}$

(c) $\operatorname{HMBC}(\rightarrow$,(d) $\operatorname{COSY}(\rightarrow$ dan NOESY $(---)$

\section{Kesimpulan}

Senyawa fenilpropanoid dengan nama skopoletin (7-hidroksi-6-metoksi-kroman2-on) telah berhasil diisolasi dari kulit umbi Ipomoea batatas L varietas IRmelati. 


\section{Daftar Pustaka}

Islam, M.S., Yoshimoto, M., Yahara, S., Okuno, S., Ishiguro, K., Yamakawa, O. (2002). Identification and Characterization of Foliar Polyphenolic Composition in Sweet potato (Ipomoea batatas L.) Genotypes. Journal of Agricultural and Food Chemistry, 50, 3718-3722.

Oki, T., Masuda, M., Osame, M., Kobayashi, M., Furuta, S., Nishiba, Y., Suda, I., (2002b). Radicalscavenging activity of hot water extract from leaves of sweet potatocultivar "Simon-1". Nippon Shokuhin Kagaku Kogaku Kaishi, 49, 683-687.
Shekhar, S., Mishra, D., Buragohain, A. K., Chakraborty, S., \& Chakraborty, N. (2015). Comparative analysis of phytochemicals and nutrient availability in two con-trasting cultivars of sweet potato (Ipomoea batatas L.). Food Chemistry, 173,957-965.

Wu, X., Sun, C., Yang, L., Zeng, G., Liu, Z., \& Li, Y. (2008). Carotene content in sweetpotato varieties from China and the effect of preparation on carotene retention in the Yanshu No. 5. Innovative Food Science and Emerging Technologies, 9,581-586. 